\title{
Interaction of uranium(VI) towards glutathione - an example to study different functional groups in one molecule
}

\author{
By L. Frost, G. Geipel*, K. Viehweger and G. Bernhard \\ Institute of Radiochemistry, Helmholtz Zentrum Dresden-Rossendorf, P.O. Box 510119, Dresden 01314, Germany
}

(Received December 22, 2009; accepted in revised form October 26, 2010)

\section{Uranium / Glutathione / Complexation / Derivatization / $U$ V-vis spectroscopy / TRLFS}

Summary. Glutathione, the most abundant thiol compound of the cell, has a great binding potential towards heavy metal ions. Hence it might influence the distribution of actinides on a cellular level. The unknown strength of the interaction of uranium(VI) with glutathione at physiologically relevant $\mathrm{pH}$ is subject of this paper and was studied with UV-vis spectroscopy and time-resolved laserinduced fluorescence spectroscopy (TRLFS). The complex stability constant of $\mathrm{UO}_{2} \mathrm{H}_{2} \mathrm{GS}^{+}, \log \beta_{121}^{0}$, was calculated to be $39.09 \pm 0.15$ and $39.04 \pm 0.02$ in case of UV-vis spectroscopy and TRLFS respectively. Therefore the average formation constant for $\mathrm{UO}_{2}{ }^{2+}+\mathrm{H}_{2} \mathrm{GS}^{-}=\mathrm{UO}_{2} \mathrm{H}_{2} \mathrm{GS}^{+}$can be assigned to be $\log K_{11}^{0}=19.83 \pm 0.15$.

Furthermore it was demonstrated that derivatization of the ligand associated with an enhancement of the ligand's spectroscopic properties can be used for the determination of complex stability constants and to assess the coordination chemistry in more detail. Using UV-vis spectroscopy, the stability constant of the complex between $\mathrm{UO}_{2}{ }^{2+}$ and glutathione pyruvate S-conjugate, a well absorbing ligand in contrast to glutathione, was calculated to be $>39.24 \pm 0.08$. Furthermore the interaction of $\mathrm{UO}_{2}{ }^{2+}$ with glutathione derivatized with the fluorescent label monobromobimane was examined with femtosecond laser fluorescence spectroscopy. Thereby the stability constant of the $1: 1$ complex was determined to be $>39.35 \pm 0.02$. Although the thiol group of glutathione was blocked a strong coordination was found. Thus a significant involvement of the thiol group in the coordination of U(VI) can be excluded.

\section{Introduction}

The release of actinides into the environment through industrial activities and the consequent uptake by plants and other living matter is of serious concern because of the highly toxic impact of actinides. To receive information about the effect and distribution of uranium on a cellular level, knowledge has to be gained about the uranium complexes formed.

Glutathione, an essential cellular antioxidant occurring ubiquitously in plants, mammals and microorganisms [1], has a great binding potential towards numerous heavy metal

\footnotetext{
*Author for correspondence (E-mail: g.geipel@hzdr.de).
}

ions [2]. Hence the process of interaction between glutathione and uranium might influence the distribution of this metal on a cellular level. Glutathione is a polydentate ligand offering two carboxylate, an amino, a thiol and two amide groups for coordination. The structure of the glutathione molelcules is shown in Fig. 1.

Because of the high electro negativity of reduced sulfhydryl groups a coordination of metals by the thiol group is found frequently and leads to the formation of metalglutathione complexes of high thermodynamic stability [3]. Nevertheless, uranium(VI) as a hard cation is expected to be coordinated by hard Lewis bases like carboxylate oxygens.

In 1977 the interaction of uranium(VI) with glutathione was studied first with electronic absorption, IR, PMR and circular dichroism spectroscopy [4]. From studies mainly carried out in the solid phase it was concluded that coordination occurs at the carboxylato groups, whereas no significant interaction with the amino and sulfhydryl group was detectable. Subsequently, the complex formation between uranyl(VI) and glutathione was studied in acidic aqueous solution by potentiometry and calorimetry [5]. In acidic solution solely a $1: 1$ complex with a stability constant $\log \beta_{11}$ of 2.24 was found. This literature source hitherto represents the only study in which a stability constant of the uranyl glutathione complex has been calculated. Also this constant is only valuable at low $\mathrm{pH}$. Hence there is a need for the determination of the stability constant of the complex at physiologically relevant $\mathrm{pH}$ and verification of that constant with additional experimental techniques in order to get a consistent result of the complex formation between uranyl and glutathione.

This paper represents the first determination of the stability constant of the uranyl glutathione complex at neutral<smiles>N[C@@H](CCC(=O)N[C@@H](CS)C(=O)NCC(=O)O)C(=O)O</smiles>

Fig. 1. Structure of the glutathione mulecule. 
$\mathrm{pH}$. For the first time UV-vis and for the purpose of validation time-resolved laser-induced fluorescence spectroscopy was used. Additionally a unique approach was made for the determination of the stability constant. By derivatization of glutathione at the thiol group the complex formation was investigated further by UV-vis and femtosecond time-resolved laser-induced fluorescence spectroscopy. Thus the involvement of the thiol group in coordination could be assessed.

In general, the study of the interaction of actinides with biologically relevant ligands is elementary for understanding the interaction of actinides in biological systems on a molecular level.

\section{Experimental}

\subsection{Solutions and reagents}

A stock solution of $0.1 \mathrm{M} \mathrm{UO}_{2}\left(\mathrm{ClO}_{4}\right)_{2}$ was used, and the exact concentration of the stock solution was determined by ICP-MS (Elan 6000, Perkin Elmer). Reduced glutathione (GSH) was of analytical grade and purchased from Duchefa, Netherlands. Glutathione stock solutions were prepared freshly for each experiment. The derivatization reagents $\beta$-fluoropyruvate and monobromobimane were purchased from Sigma-Aldrich, Germany. All solutions were prepared with $\mathrm{CO}_{2}$-free Milli-Q-water (Milli-RO/Milli-Q-System, Millipore, Molsheim, France). For all complexation experiments, ionic strength was adjusted to $0.1 \mathrm{M}$ with $\mathrm{NaClO}_{4}$ (Sigma-Aldrich, Germany). The $\mathrm{pH}$ was constantly set to 5.0 in terms of UV-vis studies of uranyl complexation by GSH. The $\mathrm{pH}$ was set to 7.4 for the remaining complexation studies to imitate plant cell cytoplasm $\mathrm{pH}$ [6]. The $\mathrm{pH}$ adjustments were made with $\mathrm{HClO}_{4}$ or $\mathrm{NaOH}$ both from Merck, Germany. The $\mathrm{pH}$ was measured using a glass electrode (Blueline $16 \mathrm{pH}$, Schott, Mainz, Germany) calibrated with standard buffers and a pH meter (InoLab720, WTW, Weinheim, Germany).

\subsection{Synthesis of glutathione derivatives}

Glutathione was derivatized with $\beta$-fluoropyruvate to create an absorbing S-conjugate according to [7]. Additionally it was found that an increase of reaction temperature to $37^{\circ} \mathrm{C}$ and keeping $\mathrm{pH}$ at 8.1 by adding $\mathrm{NaOH}$ raised reaction rate significantly. $1 \mathrm{mM}$ and $2 \mathrm{mM}$ solutions of glutathionepyruvate were used for complexation experiments.

A fluorescent glutathione S-conjugate was synthesized from reduced glutathione by labelling with monobromobimane (MBB) [8]. MBB was dissolved in pure ethanol (Riedel-de-Haën, Germany). A molar ratio of the reagents of $1: 1$ was used for the reaction. A $2 \mathrm{mM}$ glutathione-bimane stock solution was used for complexation experiments.

\subsection{UV-vis measurements}

UV-vis absorption spectroscopy experiments were performed using a Cary 50 Bio spectrometer (Varian Co.) at room temperature. The absorption spectra were recorded a) in case of complexation by glutathione from 350 to $500 \mathrm{~nm}$, b) in terms of complexation by glutathione-pyruvate from 290 to $330 \mathrm{~nm}$. Data was collected with an interval of
$0.5 \mathrm{~nm}$. The complexation studies were carried out as a function of the ligand concentration at $\left[\mathrm{UO}_{2}{ }^{2+}\right]=$ const. $=$ $0.5 \mathrm{mM}$ and $0.1 \mathrm{mM}$ for experiments with glutathione and glutathione-pyruvate respectively. Association constants of the uranyl glutathione and uranyl glutathione-pyruvate complex were determined with the factor analysis program SPECFIT [9].

\subsection{TRLFS measurements ( $\mathrm{UO}_{2}{ }^{2+}$ photoluminescence)}

A pulsed Nd:YAG laser (Minilite, Continuum Inc., Santa Clara, USA) with an emission wavelength of $266 \mathrm{~nm}$ and a repetition rate of $10 \mathrm{~Hz}$ was used for excitation of the uranyl ion. By means of a fiber optic cable the emitted signal was focused onto a spectrograph (iHR 550, Yobin-Ivon Horiba). The emission spectra were measured with an intensified CCD camera (Yobin-Ivon Horiba). Using an internal delay generator, time-resolved spectra were recorded with a delay increment of $1000 \mathrm{~ns}$. Spectra were taken from $40 \mathrm{~ns}$ after excitation of the laser up to a delay time of $34.04 \mu \mathrm{s}$. The spectra were recorded from 371 to $674 \mathrm{~nm}$ with 200 laser shots per spectrum. TRLFS measurements were carried out at a constant uranyl concentration of $4 \times 10^{-5} \mathrm{M}$. Glutathione concentration was varied from 0 up to $2 \times 10^{-4} \mathrm{M}$.

\section{5 fs-TRLFS measurements (glutathione-bimane fluorescence)}

For measuring glutathione-bimane fluorescence as a function of uranyl concentration, a pulsed femtosecond laser with a repetition rate of $1 \mathrm{kHz}$ was used. The light source consisted of a $\mathrm{Nd}: \mathrm{YVO}_{4}$ laser seeded amplifier system (Spectra Physics, Mountain View, USA). For the excitation of glutathione-bimane an emission wavelength of $266 \mathrm{~nm}$ was used.

Emitted fluorescence was focused onto a spectrograph (Spectra Pro 2300i, Acton Research, Acton, USA) and recorded by an intensified CCD camera (Picostar HR, LaVision Inc., Göttingen, Germany). With an increment of 0.1ns provided by the delay generator, spectra were collected from 0 to $20 \mathrm{~ns}$. The gate width for fluorescence detection amounted to $2 \mathrm{~ns}$. Spectra were measured in the wavelength range from 398 to $602 \mathrm{~nm}$. A more detailed description of the used system is given in [10]. The complexation studies were carried out at a glutathione-bimane concentration of $10^{-5} \mathrm{M}$ and $\left[\mathrm{UO}_{2}{ }^{2+}\right]$ varying from 0 up to $5 \times 10^{-5} \mathrm{M}$.

\subsection{Complexation models for chosen $\mathrm{pH}$ conditions}

The species distributions of $\mathrm{U}(\mathrm{VI})$ at $\mathrm{pH} 5.0$ and 7.4 and at relevant $\mathrm{UO}_{2}{ }^{2+}$ concentration $\left(\mathrm{CO}_{2}\right.$-free system, ionic strength $0.1 \mathrm{M}$ ) were calculated with the speciation program MEDUSA [11]. $\left(\mathrm{UO}_{2}\right)_{3}(\mathrm{OH})_{5}{ }^{+}$is the dominant uranyl hydroxo species for all chosen conditions. Hence the presence of this complex ion has to be taken into account when analyzing the spectral data. Thus the analysis of spectral data was based on the chemical model that $\left(\mathrm{UO}_{2}\right)_{3}(\mathrm{OH})_{5}{ }^{+}$and glutathione (or glutathione derivative) react to form a complex of the general constitution $\left(\mathrm{UO}_{2} \mathrm{H}_{n} \mathrm{GS}\right)^{(n-1)+}$, where $n$ depends on the $\mathrm{p} K_{\mathrm{a}}$ values of glutathione and the experimental $\mathrm{pH}$. 


\section{Results and discussion}

\subsection{UV-vis spectroscopy}

The complexation studies were performed at constant uranyl concentration as a function of glutathione or glutathionepyruvate concentration. UV-vis absorption spectra of solutions of increasing $\mathrm{GSH} / \mathrm{UO}_{2}{ }^{2+}$ ratio show the complexation of the uranyl ion by glutathione at $\mathrm{pH} 5.0$ (Fig. 2).

With increasing GSH concentration, absorption increases and from a concentration ratio of $1: 1$ on, a change of the absorption maxima is recognizable. These spectra were further evaluated with the factor analysis program SPECFIT. Because of the difference in the spectroscopic properties of chemical species, the recorded spectra change in dependence on the physicochemical parameter varied, which in this experiment was the ligand concentration. Keeping the physicochemical parameter $\mathrm{pH}$ constant, these UV-vis spectra of mixtures can be quantitatively resolved into their components with SPECFIT. Besides the use of SPECFIT for spectra decomposition purposes, SPECFIT also calculates reasonable equilibrium constants [12]. In the present study, eight individual spectra were used for the calculation of the association constant $\log K_{\text {Ass }}$ of a uranyl glutathione complex of a $1: 1$ constitution. The protonation state of glutathione within the complex was deduced from the $\mathrm{p} K_{\mathrm{a}}$ values of glutathione [13] and under the assumption, that the thiol group as a weak Lewis donor does not coordinate to $\mathrm{UO}_{2}{ }^{2+}$ and thus remains protonated. Hence glutathione is twofold protonated at $\mathrm{pH} 5.0$ as well as at $\mathrm{pH} 7.4$, since the carboxylic acid groups are deprotonated $\left(\mathrm{p} K_{1} 2.10, \mathrm{p} K_{2}\right.$ $3.53)$ and the thiol $\left(\mathrm{p} K_{3}\right.$ 8.65) and amino group ( $K_{4}$ 9.52) remain protonated. Regardless, whether the thiol group is derivatized, the complex association reaction can be generally given by:

$$
\begin{aligned}
\left(\mathrm{UO}_{2}\right)_{3}(\mathrm{OH})_{5}{ }^{+}+ & 3(\mathrm{HGS}-\mathrm{X})^{2-} \rightarrow \\
& 3\left(\mathrm{UO}_{2} \mathrm{HGS}-\mathrm{X}\right)+5 \mathrm{OH}^{-}
\end{aligned}
$$

In case of complexation by glutathione, $\mathrm{X}$ is the proton of the thiol group leading to $\mathrm{UO}_{2} \mathrm{H}_{2} \mathrm{GS}^{+}$as the complex formed.

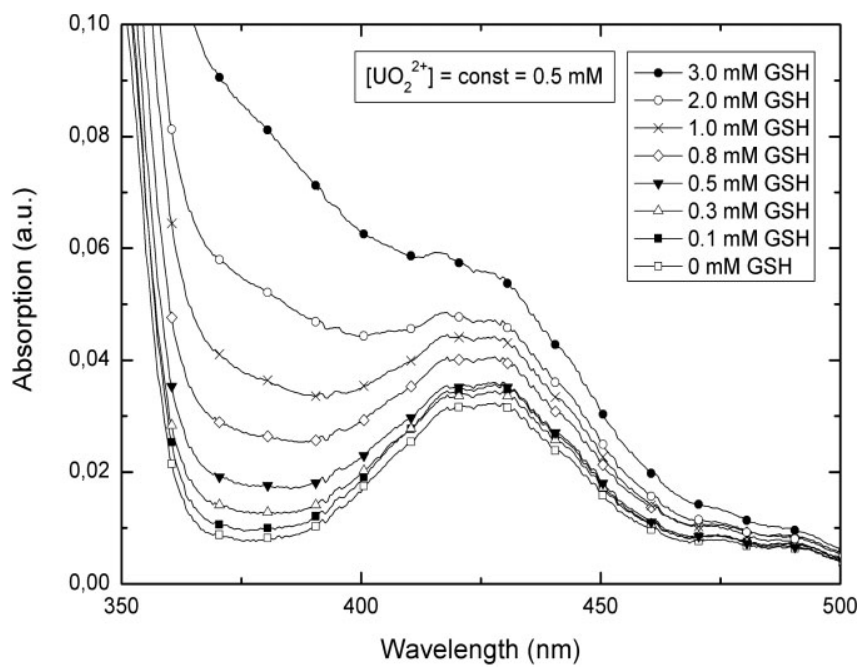

Fig. 2. UV-vis absorption spectra of $0.5 \mathrm{mM} \mathrm{UO}_{2}{ }^{2+}$ as a function of glutathione concentration at $\mathrm{pH} 5.0$ in $0.1 \mathrm{M} \mathrm{NaClO}_{4}$.

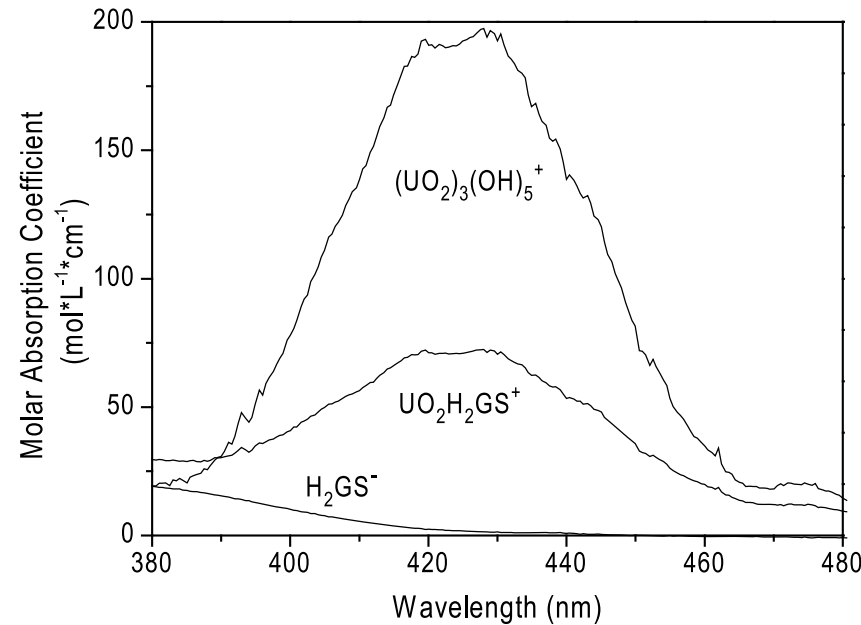

Fig. 3. Molar absorption spectra of the single components in the $\mathrm{UO}_{2}{ }^{2+}$ glutathione system.

Using SPECFIT an average $\log K_{\text {Ass }}$ of $3.82 \pm 0.15$ was calculated for the complexation of $\mathrm{UO}_{2}{ }^{2+}$ by glutathione at $\mathrm{pH}$ 5.0. The deviation given represents the standard error of the mean, SEM. The determined association constant represents an average of three concentration series.

To verify the presence of the $1: 1$ complex, SPECFIT was used for the determination of single component spectra based on the measured UV-vis spectra. Further input parameters were the stability constant of the $\left(\mathrm{UO}_{2}\right)_{3}(\mathrm{OH})_{5}{ }^{+}$ complex [14] as well as the $\mathrm{p} K_{\mathrm{a}}$ values of glutathione. $\mathrm{UO}_{2} \mathrm{H}_{2} \mathrm{GS}^{+}$was verified as the complex formed. The single component spectrum of $\mathrm{UO}_{2} \mathrm{H}_{2} \mathrm{GS}^{+}$is shown in Fig. 3 .

The determined single component spectra are reasonable in comparison to the spectra of the concentration series (Fig. 2). It can be seen that with increasing amount of glutathione a peak at approximately $420 \mathrm{~nm}$ appears because of the increasing contribution of free glutathione absorption as well as $\mathrm{UO}_{2} \mathrm{H}_{2} \mathrm{GS}^{+}$absorption. As a consequence of complexation, the absorption maximum of $\left(\mathrm{UO}_{2}\right)_{3}(\mathrm{OH})_{5}{ }^{+}$ vanishes with increasing amount of $\mathrm{UO}_{2} \mathrm{H}_{2} \mathrm{GS}^{+}$.

Investigating the coordination of $\mathrm{UO}_{2}{ }^{2+}$ by the derivatization product glutathione-pyruvate with UV-vis spectroscopy,

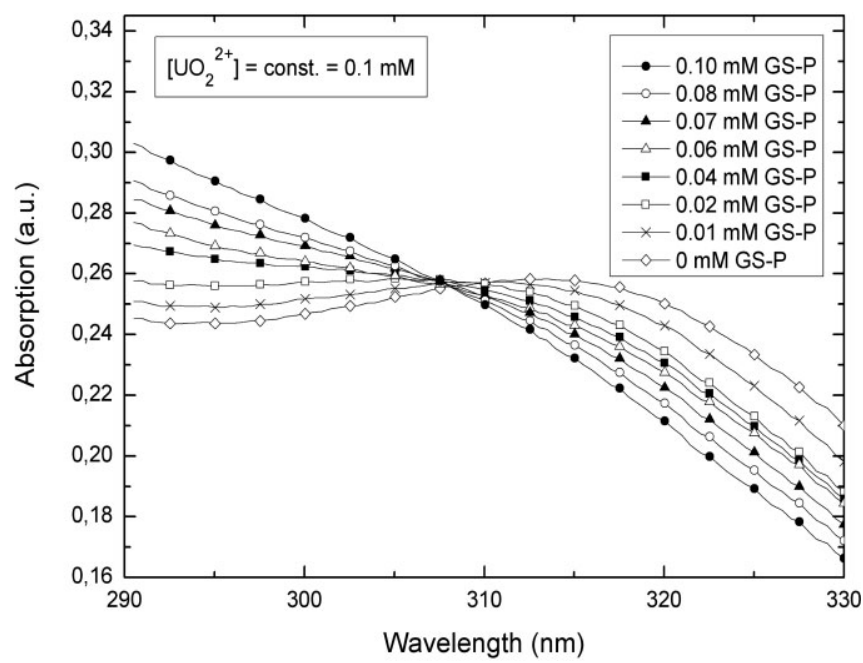

Fig. 4. UV-vis absorption spectra of $0.1 \mathrm{mM} \mathrm{UO}_{2}{ }^{2+}$ as a function of glutathione-pyruvate concentration at $\mathrm{pH} 7.4$ in $0.1 \mathrm{M} \mathrm{NaClO}_{4}$. 
the absorption spectra of the glutathione-pyruvate concentration series at constant $\mathrm{UO}_{2}{ }^{2+}$ concentration reveal an isosbestic point at $310 \mathrm{~nm}$ (Fig. 4).

These spectra were evaluated with SPECFIT with respect to the association constant of the $\mathrm{UO}_{2} \mathrm{HGS}$-pyruvate complex. The formation of the $1: 1$ complex again can be described by reaction (1), where $\mathrm{X}$ now represents the pyruvate residue. With SPECFIT an association constant $\log K_{\text {Ass }}$ of $4.27 \pm 0.08$ (SEM) was calculated. Comparing this constant to the one of the $\mathrm{UO}_{2} \mathrm{H}_{2} \mathrm{GS}^{+}$complex it can be concluded, that the thiol group is not involved in the coordination of the uranyl ion. If there were a significant contribution of the thiol group to coordination, a considerable decrease of the association constant would have resulted from derivatization. This result is consistent with literature $[4,5]$, which suggests a coordination of the uranyl ion by the carboxylate groups. Thus uranyl behaves unlike many other heavy metals as for instance Cd [2], which are preferably coordinated by the thiol group.

\subsection{TRLFS spectroscopy ( $\mathrm{UO}_{2}{ }^{2+}$ photoluminescence)}

Generated time-resolved emission spectra were evaluated using the ORIGIN 7.5G (OriginLab Corporation, USA) code. A biexponential decay function (Eq. 2) was used to describe the photoluminescence decay curve of the solutions containing $\left(\mathrm{UO}_{2}\right)_{3}(\mathrm{OH})_{5}{ }^{+}$and $\left(\mathrm{UO}_{2}\right)_{4}(\mathrm{OH})_{7}{ }^{+}$of nonnegligible amount.

$$
y=y_{0}+I_{1} \cdot \exp \left(\frac{-\left(x-x_{0}\right)}{\tau_{1}}\right)+I_{2} \cdot \exp \left(\frac{-\left(x-x_{0}\right)}{\tau_{2}}\right)
$$

In the remaining cases, in which [glutathione] leads to a significant decrease of $\left[\left(\mathrm{UO}_{2}\right)_{4}(\mathrm{OH})_{7}^{+}\right]$, Eq. (2) can be reduced to a monoexponential decay function by discarding the last addend. By applying the exponential decay function to the experimental data, the photoluminescence intensity I and lifetime $\tau$ of $\left(\mathrm{UO}_{2}\right)_{3}(\mathrm{OH})_{5}{ }^{+}$of each measured solution of the glutathione concentration series was calculated. Fig. 5 shows exemplary a photoluminescence decay curve of $\left(\mathrm{UO}_{2}\right)_{3}(\mathrm{OH})_{5}{ }^{+}$. Here a decrease of the photolumi-

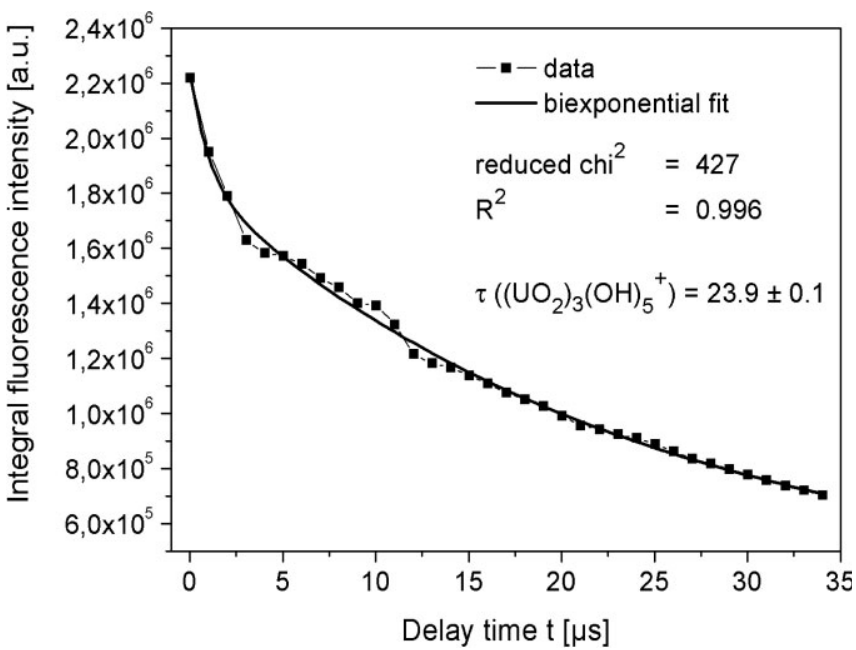

Fig. 5. Fluorescence decay curve of $4 \times 10^{-5} \mathrm{M}$ U(VI) solution at $0.1 \mathrm{M}$ ionic strength and $\mathrm{pH}$ 7.4.

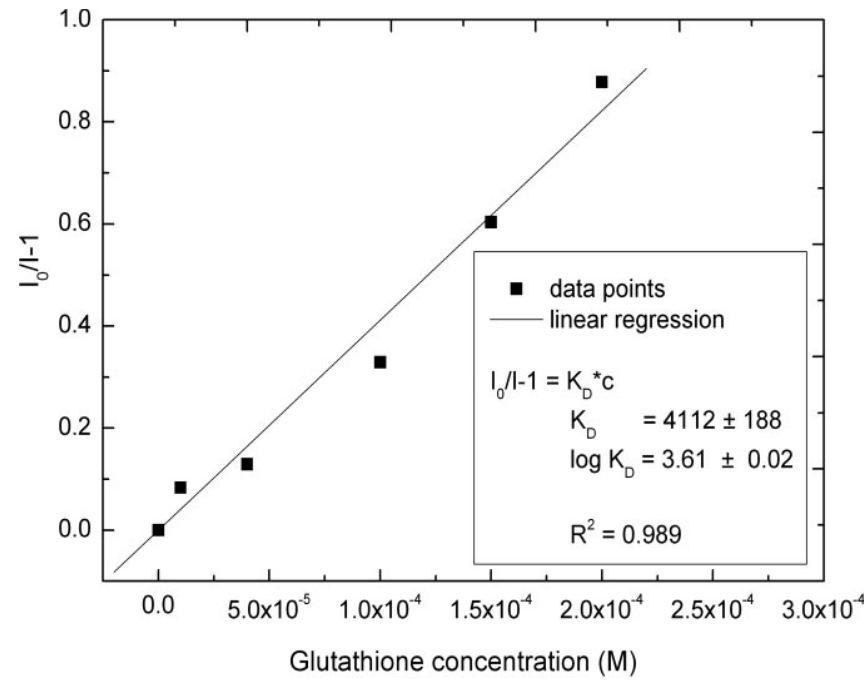

Fig. 6. Stern-Volmer plot based on $\left(\mathrm{UO}_{2}\right)_{3}(\mathrm{OH})_{5}{ }^{+}$fluorescence in dependence on [glutathione] at $\mathrm{pH}$ 7.4.

nescence intensity with increasing ligand concentration was observed. This is characteristic for a static quench process. Also a slight decrease of the photoluminescence lifetime with increasing ligand concentration was observed indicating an additional dynamic quench process caused by the ligand. Calculated photoluminescence intensities were further evaluated using the Stern-Volmer equation:

$$
\frac{I_{0}}{I}=1+K_{\mathrm{D}}[Q]
$$

where $I_{0}$ is the intensity without quencher, $K_{\mathrm{D}}$ represents the Stern-Volmer constant and $[Q]$ is the quencher/ligand concentration. In case of negligible contribution of dynamic quenching and primarily a static quench process taking place, the plot of $\left(\mathrm{I}_{0} / \mathrm{I}-1\right)$ vs. [ligand] yields a straight line whose slope is $K_{\mathrm{D}}$. $K_{\mathrm{D}}$ then directly represents the association constant of the $\mathrm{UO}_{2} \mathrm{H}_{2} \mathrm{GS}^{+}$complex. The evaluation of the photoluminescence intensities using the Stern-Volmer equation is shown in Fig. 6.

The coefficient of determination of the regression indicates, that experimental data is described well by the SternVolmer equation. Based on the data shown in Fig. 6 and a second data set, an average $\log K_{\text {Ass }}$ of $3.65 \pm 0.02$ (SEM) was calculated. This constant agrees well with the one of the $\mathrm{UO}_{2} \mathrm{H}_{2} \mathrm{GS}^{+}$complex determined with $\mathrm{UV}$-vis spectroscopy combined with SPECFIT.

\section{3 fs-TRLFS spectroscopy (glutathione-bimane fluorescence)}

The complexation of $\mathrm{UO}_{2}{ }^{2+}$ by glutathione-bimane could be assessed well with femtosecond laser fluorescence spectroscopy. In pure glutathione-bimane solution as well as in solution containing both uranyl and ligand at $\mathrm{pH} 7.4$, a monoexponential decay of the glutathione-bimane fluorescence was observed. All time-resolved fluorescence spectra of the $\mathrm{UO}_{2}{ }^{2+}$ concentration series were evaluated using a monoexponential decay function. This evaluation yielded the fluorescence intensities and lifetimes of glutathione-bimane at varying $\left[\mathrm{UO}_{2}{ }^{2+}\right]$. We observed a constant glutathionebimane fluorescence lifetime of $8.3 \pm 0.8 \mathrm{~ns}$. The given de- 


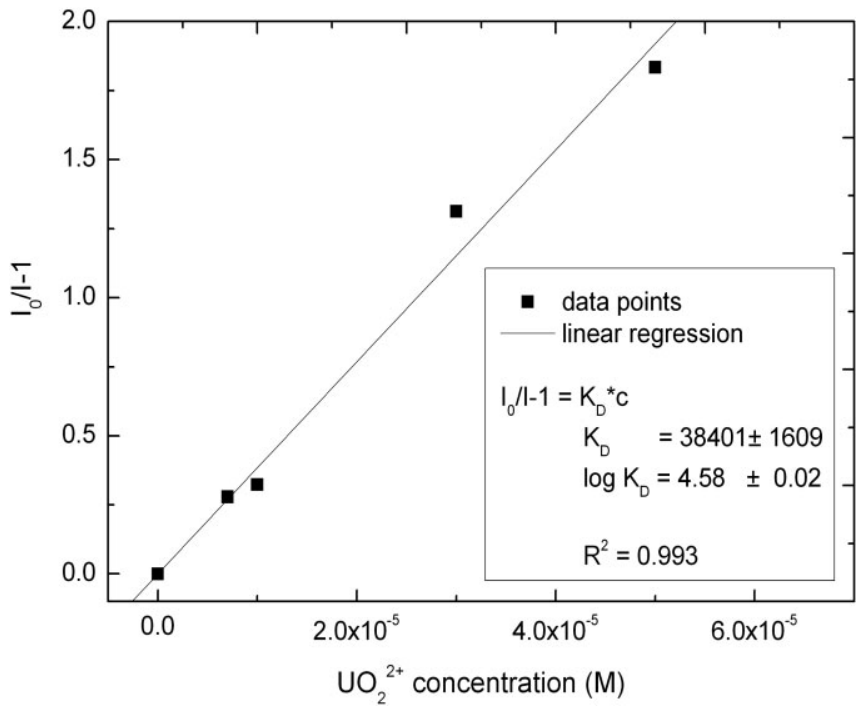

Fig. 7. Stern-Volmer plot based on glutathione-bimane fluorescence in dependence on $\left[\mathrm{UO}_{2}{ }^{2+}\right]$ at $\mathrm{pH} 7.4$.

viation represents the standard deviation. For the calculation of the mean glutathione-bimane fluorescence lifetime, lifetimes of three concentration series were averaged. Since glutathione-bimane fluorescence lifetime does not depend on $\left[\mathrm{UO}_{2}{ }^{2+}\right]$, a dynamic quench process can be ruled out. The static quench effect, which was indicated by the glutathionebimane fluorescence decrease at increasing $\left[\mathrm{UO}_{2}^{2+}\right.$, again was used to determine the association constant of the complex. The application of the Stern-Volmer equation (Eq. 3) to the experimental data is shown in Fig. 7.

The experimental data is represented well by the SternVolmer equation, as Fig. 7 shows. The linear fit of the plotted data yielded 0.99 for $R^{2}$. From the slope of the regression the association constant $\log K_{\text {Ass }}$ of the $\mathrm{UO}_{2}$ HGS-bimane complex was determined to be $4.58 \pm 0.02$. Averaging three series of measurements, the association constant still amounts to $4.58 \pm 0.02$ indicating a very small deviation. Since no significant decrease of the association constant associated with derivatization of glutathione was observed, again an involvement of the thiol group in coordination of $\mathrm{UO}_{2}{ }^{2+}$ can be excluded. Thus it could be confirmed that the SH group of glutathione does not contribute to coordination of the uranyl ion significantly.

This assignment is based on the assumption, that the chemical bond between glutathione and pyruvate and monobrombimane, respectively, will be not broken during the complex formation with the uranyl ion.

\subsection{Determination of the complex stability and formation constants}

All hitherto calculated constants just represent association constants. For a conversion of those into complex stability constants, the formation constant of $\left(\mathrm{UO}_{2}\right)_{3}(\mathrm{OH})_{5}{ }^{+}$[14] as well as the $\mathrm{p} K_{\mathrm{a}}$ values of the thiol and amino group of glutathione [13] have to be considered. This can be achieved by applying the following general system of equations:

$$
\begin{aligned}
& \mathrm{UO}_{2}{ }^{2+}+5 / 3 \mathrm{H}_{2} \mathrm{O} \rightarrow 1 / 3\left(\mathrm{UO}_{2}\right)_{3}(\mathrm{OH})_{5}{ }^{+}+5 / 3 \mathrm{H}^{+} \\
& 5 / 3 \mathrm{H}^{+}+5 / 3 \mathrm{OH}^{-} \rightarrow 5 / 3 \mathrm{H}_{2} \mathrm{O}
\end{aligned}
$$

Table 1. Summary of calculated stability constants of $\mathrm{UO}_{2}{ }^{2+}$ glutathione and $\mathrm{UO}_{2}{ }^{2+}$ glutathione $\mathrm{S}$-conjugate species at zero ionic strength.

\begin{tabular}{lccc}
\hline Species & Method & $\log \beta_{121}^{0}$ & $\mathrm{SEM}^{a}$ \\
\hline $\mathrm{UO}_{2} \mathrm{H}_{2} \mathrm{GS}^{+}$ & UV-vis & 39.09 & \pm 0.15 \\
$\mathrm{UO}_{2} \mathrm{H}_{2} \mathrm{GS}^{+}$ & TRLFS & 39.04 & \pm 0.02 \\
$\mathrm{UO}_{2} \mathrm{HGS}_{\text {-pyruvate }}$ & UV-vis & $>39.24$ & \pm 0.08 \\
$\mathrm{UO}_{2} \mathrm{HGS}$-bimane & TRLFS & $>39.35$ & \pm 0.02 \\
\hline
\end{tabular}

a: SEM: standard error of the mean.

$$
\begin{aligned}
& \mathrm{GS}^{3-}+\mathrm{H}^{+} \rightarrow \mathrm{HGS}^{2-} \\
& \mathrm{HGS}^{2-}+\mathrm{X} \rightarrow \mathrm{HGS}^{2-} \mathrm{X}^{2-} \\
& 1 / 3\left(\mathrm{UO}_{2}\right)_{3}(\mathrm{OH})_{5}{ }^{+}+\mathrm{HGS}-\mathrm{X}^{2-} \rightarrow \\
& \mathrm{UO}_{2} \mathrm{HGS}-\mathrm{X}+5 / 3 \mathrm{OH}^{-} \\
& \mathrm{UO}_{2}{ }^{2+}+\mathrm{GS}^{3-}+\mathrm{H}^{+}+\mathrm{X} \rightarrow \mathrm{UO}_{2} \mathrm{HGS}-\mathrm{X}
\end{aligned}
$$

In case of complexation of uranyl by glutathione, reaction Eq. (7) represents the protonation of the thiol group. Hence the protonation constant of the thiol group is used to describe the equation. If the thiol group is derivatized, $X$ is either the pyruvate or bimane residue. Consequently no information is available on the influence of the derivatization on the constant associated with this equation. Resulting complex stability constants described by Eq. (9) are only valuable at an ionic strength of $0.1 \mathrm{M}$. For the purpose of a better comparison to literature values, the determined stability constants were extrapolated to infinite dilution in accordance to the procedure described by [15]. Table 1 summarizes the complex stability constants calculated at infinite dilution.

To allow also a comparison to formation constants of the literature, the determined complex stability constants were additionally converted to complex formation constants described by the reaction:

$$
\mathrm{UO}_{2}{ }^{2+}+\mathrm{H}_{2} \mathrm{GS}^{-} \rightarrow \mathrm{UO}_{2} \mathrm{H}_{2} \mathrm{GS}^{+} .
$$

For this purpose the $\mathrm{p} K^{0}$ values of the thiol and amino group of glutathione, which were deduced from $\mathrm{p} K_{\mathrm{a}}$ values given in [13] and amount to 9.08 and 10.16 respectively, were subtracted from $\log \beta_{121}^{0}$. Therefore the average formation constant for Eq. (10) can be assigned to be $\log K_{11}^{0}=19.83 \pm$ 0.15 .

These results indicate that glutathione as well as the glutathione S-conjugates form strong complexes with the uranyl ion. Based on the determined complex formation constant of $\mathrm{UO}_{2} \mathrm{H}_{2} \mathrm{GS}^{+}$a speciation diagram was calculated with MEDUSA [11]. This diagram (Fig. 8) points out that even in presence of carbonate $\mathrm{UO}_{2}{ }^{2+}$ speciation is affected significantly by the presence of glutathione at $\mathrm{pH}<10$.

In comparison of the complex stability constants determined to the only literature value available, which is just valuable at low $\mathrm{pH}$ [5], a great discrepancy is observed. This might be attributed to the difference in measurement $\mathrm{pH}$. Since complex stability constants are strongly dependent on associated protons, this could be a reasonable explanation for the discrepancy. Although no exact complex stability constant calculation could be carried out in case of derivatization of the ligand, the comparison of all calculated association constants shows clearly that the thiol group 


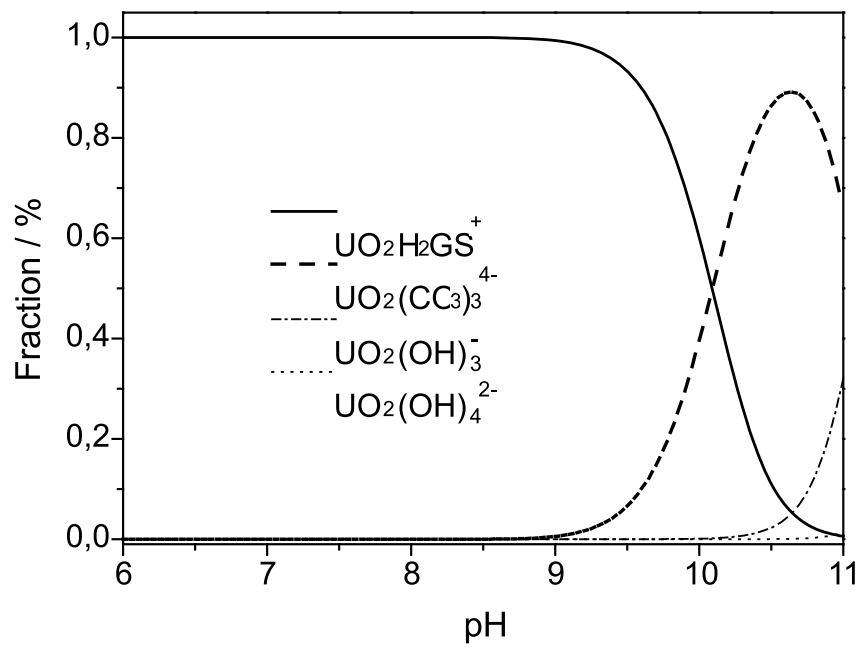

Fig. 8. Speciation diagram for $\mathrm{U}(\mathrm{VI})$ in presence of glutathione and carbonate; $[\mathrm{U}(\mathrm{VI})]=2 \times 10^{-5} \mathrm{M},[\mathrm{GSH}]=2 \times 10^{-5} \mathrm{M},\left[\mathrm{CO}_{3}{ }^{2-}\right]=$ $1 \times 10^{-3} \mathrm{M}, I=0.1 \mathrm{M}$.

of glutathione can not be involved in the coordination of uranyl.

\section{Conclusion}

Conclusively the combination of UV-vis spectroscopy with the factor analysis program SPECFIT represents a sensitive method to explore the complexation of uranyl by glutathione in aqueous solution. TRLFS measurements combined with Stern-Volmer evaluation have produced almost an identical result for the complexation of $\mathrm{UO}_{2}{ }^{2+}$ by glutathione. Thus a validation of the calculated constant could be achieved by using an additional experimental technique. The present work aimed at addressing the question of the influence of glutathione on uranium(VI) complexation on a molecular level. From the in vitro model complexation experiments in this work the formation of a strong $\mathrm{UO}_{2}{ }^{2+}$ glutathione complex can be concluded, indicating the unique potential of this bioligand to bind $\mathrm{UO}_{2}{ }^{2+}$. This becomes clear especially in comparison to uranyl complexes with other bioligands of cellular relevance. Thus the present work contributes to an improved understanding of $\mathrm{UO}_{2}{ }^{2+}$ coordination on a molecular level. Last concern of this paper was to depict the po- tential of ligand derivatization to assess metal coordination chemistry more detailed. In our study from ligand derivatization experiments it could be concluded that one of the four major potential binding sites of the glutathione molecule is certainly not involved in $\mathrm{UO}_{2}{ }^{2+}$ coordination.

\section{References}

1. Kidd, P. M.: Glutathione: systemic protectant against oxidative and free radical damage. Altern. Med. Rev. 1, 155 (1997).

2. Singh, B. K.: Complexation behaviour of glutathione with metal ions. Asian J. Chem. 17, 1 (2005).

3. Ballatori, N., Clarkson, T. W.: Biliary secretion of glutathione and of glutathione metal-complexes. Fundam. Appl. Toxicol. 5, 816 (1985).

4. Marzotto, A.: Uranyl complexes of glutathione. J. Inorg. Nucl. Chem. 39, 2193 (1977).

5. Bismondo, A., Rizzo, L.: Thermodynamics of the complex formation between uranyl(VI) and some polypeptides in aqueous solution. Thermochim. Acta 196, 131 (1992).

6. Roberts, J. K. M., Ray, P. M., Wade-Jardetzky, N., Jardetzky, O.: Estimation of cytoplasmic and vacuolar $\mathrm{pH}$ in higher plant cells by 31P-NMR. Nature 283, 870 (1980).

7. Avi-Dor, Y., Lipkin, R.: A spectrophotometric method for the determination of reduced glutathione. J. Biol. Chem. 233, 69 (1957).

8. Kosower, N. S., Kosower, E. M., Newton, G. L., Ranney, H. M.: Bimane fluorescent labels: labeling of normal human red cells under physiological conditions. Proct. Natl. Acad. Sci. USA 76, 3382 (1979).

9. Binstead, R. A., Zuberbühler, A. D., Jung, B.: SPECFIT/32, Version 3.0.40, Spectrum Software Associates, Marlborough (2007).

10. Geipel, G., Acker, M., Vulpius, D., Bernhard, G., Nitsche, H., Fanghänel, T.: An ultrafast time-resolved fluorescence spectroscopy system for metal ion complexation studies with organic ligands. Spectrochim. Acta 60, 417 (2004).

11. Puigdomènech, I.: MEDUSA Software, 16 bit version, http:// www.kemi.kth.se/medusa/ (2004).

12. Gampp, H., Maeder, M., Meyer, C. J., Zuberbühler, A. D.: Calculation of equilibrium constants from multiwavelength spectroscopic data -2 Specfit: two user-friendly programs in basic and standard fortran 77. Talanta 32, 257 (1985).

13. Rey, N. A., Howarth, O. W., Pereira-Maia, E. C.: Equlibrium characterization of the As(III)-cysteine and the As(III)-glutathione systems in aqueous solution. J. Inorg. Biochem. 98, 1151 (2004).

14. Guillaumont, R., Mompean, F. J.: Update on the Chemical Thermodynamics of Uranium, Neptunium, Plutonium, Americium and Technetium. Vol. 5, Elsevier, Amsterdam (2003).

15. Grenthe, I., Wanner, H.: Guidelines for the extrapolation to zero ionic strength. TDB-2, NEA web page document, http://www.nea. $\mathrm{fr} / \mathrm{html} / \mathrm{dbtdb} /$ guidelines/tdb2.pdf (2000). 